Check for updates

Cite this: RSC Adv., 2017, 7, 21796

Received 1st February 2017 Accepted 23rd March 2017

DOI: 10.1039/c7ra01343d

rsc.li/rsc-advances

\section{Sunflower oil-based hyperbranched alkyd/ spherical ZnO nanocomposite modeling for mechanical and anticorrosive applications $\uparrow$}

\author{
Mohamed S. Selim, ${ }^{\text {ab }}$ Mohamed A. Shenashen, ${ }^{\text {ab }}$ Ahmed Elmarakbi, ${ }^{\text {*c }}$ Ashraf M. EL- \\ Saeed, ${ }^{\text {b }}$ Mahmoud M. Selim ${ }^{\text {d }}$ and Sherif A. El-Safty (D) *a
}

\begin{abstract}
Approaches for designing advanced nanomaterials with hyperbranched architectures and lack of volatile organic content (VOC) have attracted considerable attention. In this study, eco-friendly hyperbranched alkyd resins for mechanical and anticorrosive coatings with high solid content were successfully synthesized based on sunflower oil (SFO) via a polyesterification approach. These resins are characterized by energy-efficient polymer synthesis, lack of gelation properties, high functionality, and low viscosity. A chemical precipitation process was used to fabricate zinc oxide $(\mathrm{ZnO})$ spherical nanostructures with controlled diameters and morphologies. A series of conformal, novel, low-cost SFO-based hyperbranched alkyd/spherical ZnO nanocomposites were fabricated through an ex situ method. Various nanofiller concentrations were distributed to establish synergetic effects on the micronano binary scale performance of the materials. The features of the nanocomposites, including the molecular weight, acid and hydroxyl values of the prepared alkyd resins, were concomitantly assessed through various standard tests. The nanocomposites were also subjected to various tests to determine their surface adhesion and mechanical properties, such as impact, T-bending, crosscut, and abrasion resistance tests. Furthermore, the physico-mechanical properties, anticorrosive behavior, thermal stabilities and cellular cytotoxicities of the fabricated materials were assessed. The anticorrosive features of the nanocomposites were investigated through salt spray tests in $5 \mathrm{wt} \% \mathrm{NaCl}$. The results indicate that well-dispersed $\mathrm{ZnO}$ nanospheres $(0.5 \%)$ in the interior of the hyperbranched alkyd matrix improve the durability and anticorrosive attributes of the composites; thus, they exhibit potential applications in ecofriendly surface coatings.
\end{abstract}

\section{Introduction}

The adverse effects of volatile organic content (VOC) on the environment have directed research in the coating industry toward eco-friendly solutions involving materials with low solvent amounts and high solid contents. ${ }^{1,2}$ These solutions require the utilization of polymers with low molecular weights and viscosities. ${ }^{3,4}$ Alkyd coatings are widely used in corrosion protection because of their commercial feasibility, facile application, and biodegradability. ${ }^{5}$ Dendritic resins are promising

${ }^{a}$ National Institute for Materials Science (NIMS), 1-2-1 Sengen, Tsukuba-shi, Ibaraki-ken 305-0047, Japan. E-mail: sherif.elsafty@nims.go.jp

${ }^{b}$ Petroleum Application Department, Egyptian Petroleum Research Institute, Nasr City 11727, Cairo, Egypt

'Automotive Composites Group, Faculty of Engineering and Advanced and Manufacturing, University of Sunderland, Sunderland SR6 ODD, UK. E-mail: ahmed. elmarakbi@sunderland.ac.uk

${ }^{d}$ Department of Mathematics, Al-Aflaj College of Science and Human Studies, Prince Sattam Bin Abdulaziz University, Al-Aflaj 710-11912, Saudi Arabia

$\dagger$ Electronic supplementary information (ESI) available. See DOI: $10.1039 / \mathrm{c} 7 \mathrm{ra} 01343 \mathrm{~d}$ eco-friendly coatings because of their high solid content and low viscosity characteristics. The application of dendritic polymers, including hyperbranched polymers and dendrimers, has progressed because of their excellent structural characteristics, such as lack of entanglement and high surface functionality. ${ }^{6,7}$ However, hyperbranched polymers outperform dendrimers because the former are prepared in single-step protocols without requiring multi-purification procedures. $^{8}$ Hyperbranched architectures also exhibit many advantages over conventional linear analogs. ${ }^{9}$ The hyperbranched polymer structure possesses a high branching degree, low viscosity, and low molecular weight, as well as abundant surface functional groups and accessible monomers. ${ }^{10}$ These unique features of hyperbranched polymers render them suitable for use in ecofriendly paints with low VOC; in these products, the low polymer viscosity reduces the required amount of VOC thinner. ${ }^{\mathbf{1 0 , 1 1}}$ Moreover, increasing the number of terminal groups increases the curing rate. Polyesters are the most commonly used hyperbranched matrices. ${ }^{\mathbf{1 1}}$ Hyperbranched polyesters are prepared from mutually reactive multi-functional monomers through the $\mathrm{A}_{2}+\mathrm{B}_{3}$ methodology. This facile method uses simple 
multifunctional monomers to obtain hyperbranched polyesters through proper selection of monomer stoichiometry and control of the reaction conditions. ${ }^{12}$ Polyesters possess superior chemical resistance, good mechanical performance, high gloss levels, excellent flow, and dynamic curing properties. ${ }^{13}$ When these polyesters are modified with fatty acids, alkyd resins are obtained. ${ }^{14}$ Alkyd resins are versatile polymers that are used in coatings because of their excellent mechanical, wetting, and durability characteristics. Alkyd resins account for approximately $50 \%$ of all resins consumed in protective paint applications. ${ }^{15,16}$ Designing alkyd polymers using vegetable oils is a promising sustainable energy strategy because of their structural versatility, economic properties, low cost, and facile processing. ${ }^{\mathbf{8}, 16}$ Vegetable oils are commonly used in scientific research as a feedstock for polymer synthesis because of their biodegradability, flexibility due to their long alkyl chains, and eco-friendly characteristics.

The sunflower plant, which belongs to the Asteraceae family, can withstand drought, heat, and cold stress and also readily adapts to various soils and climate conditions. ${ }^{17}$ Sunflower oil (SFO) contains high amounts of unsaturated long-chain fatty acids, such as oleic acids, and is applicable for the synthesis of nanoparticles. ${ }^{18}$ SFO is used to modify alkyd resins and obtain hydroxylated polyester-derived materials. SFO-based hyperbranched alkyds exhibit excellent color retention and weather resistance, superior durability in exterior finishes, and good anti-corrosive resistance. ${ }^{19}$ Organic/inorganic hybrid nanocomposites are useful to improve coating properties; the intercalation of nanofillers and their bonds to the polymer matrix chains leads to high surface reactivity. ${ }^{20,21}$

Nanocomposite coatings based on alkyd resins have attracted considerable interest in coating materials with heavy duty characteristics. ${ }^{22}$ These coatings improve the physical, mechanical, chemical, anticorrosive, antimicrobial, anti-fog, and self-cleaning properties of materials. ${ }^{\mathbf{2 3 2}}$ Non-metal oxides, specifically ZnO particles, possess various advantages, such as low cost, ecofriendly properties, antibacterial activity, and anticorrosive properties; thus, they are applied in the fields of physics, chemistry, materials engineering, and solar cell fabrication. ${ }^{25-27}$ Changing the morphology of the $\mathrm{ZnO}$ nanoparticles from microrods to nanospheres by modifying the $\mathrm{pH}$ results in efficient anticorrosive properties. ${ }^{28}$ Hyperbranched nanocomposites endow alkyd paints with two advantages: (i) prevention of VOC problems; and (ii) improved properties. ${ }^{29}$ Individual constituent attributes, such as volume fraction, nanofiller type and morphology, and interfacial properties, are the main factors in determining the behavior of alkyd composites.

This work reports an eco-friendly, low-cost technique for designing alkyd resins with low VOC through functionalization of SFO. The fabricated SFO-based hyperbranched alkyd/spherical $\mathrm{ZnO}$ nanocomposites were evaluated. The importance of nanofiller dispersion was highlighted by investigating the improvements in the mechanical, physical, and anticorrosive properties of the resins. The successful application of alkyd nanocomposites with superior properties was confirmed through thermal, mechanical, and anticorrosive measurements.

\section{Materials and methods}

\subsection{Materials}

Sebacic acid (decanedioic acid, (HOOC) $\left.\left(\mathrm{CH}_{2}\right)_{8}(\mathrm{COOH}), 99 \%\right)$, trimethylol propane (TMP, $\mathrm{CH}_{3} \mathrm{CH}_{2} \mathrm{C}\left(\mathrm{CH}_{2} \mathrm{OH}\right)_{3}, 99 \%$ ), p-toluene sulfonic acid (PTSA, $\mathrm{CH}_{3} \mathrm{C}_{6} \mathrm{H}_{4} \mathrm{SO}_{3} \mathrm{H}$ ) and anhydrous ethanol (AR) were purchased from Sigma-Aldrich, Germany. SFO and all driers, including cobalt octoate $\left(\mathrm{C}_{16} \mathrm{H}_{30} \mathrm{CoO}_{4}\right)$, manganese octate ( $\mathrm{Mn}$ $\left.\left[\mathrm{OOCCH}\left(\mathrm{C}_{2} \mathrm{H}_{5}\right) \mathrm{C}_{4} \mathrm{H}_{9}\right]_{2}\right)$ and lead octoate $\mathrm{Pb}\left[\mathrm{OOCCH}\left(\mathrm{C}_{2} \mathrm{H}_{5}\right) \mathrm{C}_{4} \mathrm{H}_{9}\right]_{2}$, were obtained from Merck, India and were used as received. Zinc acetate dehydrate $\left(\mathrm{Zn}\left(\mathrm{CH}_{3} \mathrm{COO}\right)_{2} \cdot 2 \mathrm{H}_{2} \mathrm{O}, \mathrm{AR}\right)$, di-ethylene glycol (DEG, $\left.\mathrm{C}_{4} \mathrm{H}_{10} \mathrm{O}_{3}, \mathrm{AR}\right)$, and polyethylene glycol (400, AR) were acquired from Acros Company (Belgium). All solvents were of analytical reagent grade and were used as received.

\subsection{Preparation of SFO-based hyperbranched alkyd resin}

2.2.1. Synthesis of hyperbranched polyester. The hyperbranched polyester was synthesized from sebacic acid and TMP through a polycondensation reaction and the $\mathrm{A}_{2}+\mathrm{B}_{3}$ methodology. A $[-\mathrm{OH}] /[-\mathrm{COOH}]$ stoichiometry of approximately 2.0 was established using $32.9 \mathrm{~g}$ sebacic acid and $29.1 \mathrm{~g}$ TMP in the presence of $0.5 \%$ P-TSA $(0.31 \mathrm{~g})$ as an acid catalyst under inert nitrogen. The polycondensation reaction was performed at 150 $\pm 5{ }^{\circ} \mathrm{C}$ for $8 \mathrm{~h}$. The reaction vessel was cooled overnight, and a rotary evaporator was used to remove any unreacted monomers. The obtained polymer yield was approximately $92 \%$. The ${ }^{1} \mathrm{H}-\mathrm{NMR}$ data (300 MHz, DMSO) were 1.00-1.17 ( $\mathrm{CH}_{3}-\mathrm{TMP}$ ), $3.42\left(\mathrm{CH}_{2}-\mathrm{OH}\right), 3.97\left(\mathrm{CH}_{2}-\mathrm{OR}\right)$, and $4.54 \mathrm{ppm}\left(\mathrm{CH}_{2}-\mathrm{OH}\right.$ ends).

2.2.2. SFO-based hyperbranched alkyd resin preparation. A newly developed vegetable oil based on alkyd resin with hyperbranched architectures was prepared using the prepared hyperbranched polyester (49.85 g). The terminals $(-\mathrm{OH})$ of the hyperbranched polyester were reacted with SFO fatty acids $(10.34 \mathrm{~g})$ in the presence of $0.5 \%(0.3 \mathrm{~g})$ P-TSA. The reaction was performed in an oil bath equipped with a magnetic stirrer at $215{ }^{\circ} \mathrm{C}$ under nitrogen atmosphere. The reaction temperature was kept constant until the acid number reached 10 to $15 \mathrm{mg}$ $\mathrm{KOH}$ per $\mathrm{g}$. The product yield was $82 \%$, and the ${ }^{1} \mathrm{H}-\mathrm{NMR}$ data in the chloroform solution at $300 \mathrm{MHz}$ were $0.95-1.3\left(\mathrm{CH}_{3}-\right.$ protons of TMP and SFO fatty acids), 1.6-2.7 ( $\mathrm{CH}_{2}$ and $\mathrm{CH}$ protons of fatty acids $), 4.4\left(\mathrm{CH}_{2}-\mathrm{OR}\right)$ and $5.30 \mathrm{ppm}(-\mathrm{CH}=\mathrm{CH}-)$ (ESI, Fig. S1†).

\subsection{Fabrication of stabilized $\mathrm{ZnO}$ nanospheres}

Unique $\mathrm{ZnO}$ nanospheres were synthesized through precipitation without performing additional surface modification. ${ }^{30,31}$ Briefly, $1.5 \mathrm{~g}$ of the zinc precursor was added to $125 \mathrm{~mL}$ of DEG and stirred for $10 \mathrm{~min}$. The solution was ultrasonicated for $15 \mathrm{~min}$ and transferred to a two-neck flask. $0.16 \mathrm{~g}$ of PEG in ethyl alcohol was added dropwise to the flask under vigorous stirring. The temperature was increased to $200{ }^{\circ} \mathrm{C}$ for 10 hours. Afterward, the temperature was reduced gradually to RT, and the reaction was terminated overnight to allow settling of the produced NPs. The sample was washed with ethyl alcohol, and the NPs were collected through centrifugation and dried under vacuum. 


\subsection{Preparation of coating films}

Commercial carbon steel strips were utilized in the experiment. The energy-dispersive X-ray (XEDS) spectroscopy results for carbon steel illustrated a carbon : iron weight percentage of $2.8: 97.2 \%$. The carbon steel was polished using typical-sized SiC papers $\left(180,320\right.$, and 500), cleaned, and rinsed with $\mathrm{DI}-\mathrm{H}_{2} \mathrm{O}$, ethanol, and 2-propanone. After air drying, the degreased carbon steel surface was prepared for the unfilled and filled polymer nanocomposites with driers. Paint application was performed on $170 \mathrm{~mm} \times 90 \mathrm{~mm} \times 1 \mathrm{~mm}$ and $90 \mathrm{~mm} \times 90 \mathrm{~mm} \times 1 \mathrm{~mm}$ carbon steel strips for mechanical and anticorrosive studies.

\subsection{Film formation of SFO-based hyperbranched alkyd/ spherical ZnO nanocomposite coatings}

Film formation and curing of the prepared virgin SFO-based hyperbranched alkyd polymer were performed through solution casting. Alkyd resin (86.7 wt\%) was mixed with $10 \mathrm{wt} \%$ methylbenzene and turpentine (1:1 mixing ratio). The desired amounts of driers, including cobalt, calcium, and zirconium solutions, were $0.7 \%, 0.7 \%$, and $1.9 \%$ by weight of the total formulation, respectively. These driers were mixed under constant stirring to produce homogeneous solutions; then, they were applied on the steel surface using a film applicator and allowed to dry at $25{ }^{\circ} \mathrm{C}$ under $40 \%$ relative humidity. The driers were placed in an oven at $90^{\circ} \mathrm{C}$ for $2.5 \mathrm{~h}$ and then maintained at RT for 2 days to accelerate the drying process. The prepared nanocomposites were cured using the solution casting technique mentioned above. $\mathrm{ZnO}$ nanospheres of various concentrations $(0.01 \%, 0.05 \%, 0.1 \%, 0.5 \%, 1 \%, 3 \%$, and $5 \%)$ were sonicated for $15 \mathrm{~min}$ in a mixture of turpentine and methylbenzene $(1: 1)$. The SFO-based hyperbranched alkyd matrix ( 86.7 wt\% to (0 to 5 ) wt $\% \mathrm{ZnO}$ nanosphere solution) was solubilized in $10 \mathrm{wt} \%$ of the utilized solvent under continuous stirring. Similar procedures were applied as described in the curing step to obtain a coating film with $150 \mu \mathrm{m}$ thickness. All the formulations were characterized by various tests.

\subsection{Apparatus}

Many investigation techniques were performed on the designed polymer and its nanocomposites with ZnO nanospheres.

2.6.1. FTIR spectroscopic data. FTIR analysis was conducted using a spectrometer (Thermo-Fischer Nicolet ${ }^{\mathrm{TM}}$ iS $^{\mathrm{TM}} 10$, United States). The scan region and spectral resolution were 500 to 3900 $\mathrm{cm}^{-1}$ and $0.5 \mathrm{~cm}^{-1}$, respectively. The samples were diluted by casting with $\mathrm{KBr}$, and the blend was pressed into a thin wafer.

2.6.2. Proton nuclear magnetic resonance ( $\left.{ }^{1} \mathbf{H}-\mathrm{NMR}\right)$ analysis. Analysis was performed using a spectrometer (Varian Mercury $300 \mathrm{VX}$, United States) at $300 \mathrm{MHz}$. The sample (3 wt\%) was dissolved in chloroform with the internal standard tetramethylsilane $\left(\mathrm{Me}_{4} \mathrm{Si}\right)$.

2.6.3. Gel permeation chromatography (GPC) analysis. Analysis was performed using a spectrometer (Varian Mercury $300 \mathrm{VX}$, United States) at $300 \mathrm{MHz}$. The sample (3 wt\%) was dissolved in chloroform with the internal standard tetramethylsilane $\left(\mathrm{Me}_{4} \mathrm{Si}\right)$.
2.6.4. Thermal analysis. Thermal gravimetric analysis (TGA) provides complete data regarding the thermal stabilities of polymers and composite materials. Analysis was performed in a DSC-TGA instrument model Q600 (USA) equipped with a refrigerated cooling system. The coated specimens were scanned at $10{ }^{\circ} \mathrm{C}$ to $700{ }^{\circ} \mathrm{C}$ under inert nitrogen atmosphere.

2.6.5. X-ray diffraction (XRD) and quasi-elastic light scattering (QLS) analysis. The crystallinities and phase purities of the nano-ZnO particles and composites were detected through XRD analysis using a diffractometer (PANalytical X'Pert PRO, Netherlands). The XRD diffraction patterns of nano-ZnO powder were obtained using $\mathrm{CuK} \alpha$ radiation, a $2 \theta$ angle of $20^{\circ}$ to $80^{\circ}$, and an interatomic spacing of 1.23 to $2.82 \AA$. QLS studies were performed on a Brookhaven particle size analyzer (90Plus, United States) to measure the diameters and distributions of the nano-ZnO particles.

2.6.6. Transmission electron microscopy (TEM) studies. The morphologies and particle diameters of the nano-ZnO particles were determined by a JEM2100 LaB6 high-resolution TEM microscope (Japan) at $200 \mathrm{kV}$. The particles were ultrasonicated in ethyl alcohol for $10 \mathrm{~min}$, and two drops of the solution were placed onto carbon-coated TEM grids prior to image capture. Selected area diffraction (SAD) analysis was performed to detect the lattice planes and determine the crystal structures. For the tailored SFO-based hyperbranched alkyd/ spherical ZnO nanocoating layers, 100 to $150 \mathrm{~nm}$ slices of the film interlayers were prepared using an ultramicrotome (LKB Nova, Austria) with glass and diamond knives. The elemental composition of the ZnO NPs was analyzed using XEDS (X-Max 50 , Oxford Instruments, USA) at $30 \mathrm{kV}$.

2.6.7. Field-emission scanning electron microscopy (FESEM). Shape and surface topology data were obtained through FE-SEM imaging on a JEOL JSM530 (Japan) instrument at 30 $\mathrm{keV}$. The samples were sonicated in ethyl alcohol, and two drops of the solution were settled on a glass slide and air dried.

\subsection{Testing techniques}

2.7.1. Acid value analysis of the prepared hyperbranched alkyd resin. Analysis was performed based on ASTMD 1639-90 using a previously reported methodology. ${ }^{31,32}$ Briefly, $1 \mathrm{~g}$ of the prepared SFO-based hyperbranched alkyd sample was diluted in $20 \mathrm{~mL}$ of the neutralized solvent mixture (xylene/isopropanol $50: 50$ ) and titrated with a standard solution of $0.5 \mathrm{M}$ potassium hydroxide $(\mathrm{KOH})$ with phenolphthalein as indicator. The mean of three analytical experiments was reported. The following equation was used to determine the acid value of the prepared hyperbranched polymer: $:^{31,32}$

$$
\text { Acid value }=\left(56.1 \times C_{\mathrm{KOH}} \times A\right) / B
$$

where $A$ represents the consumed $\mathrm{KOH}$ (in milliliters), and $B$ represents the sample mass (in grams).

2.7.2. Investigation techniques of the cured unfilled and filled nanocomposites. The prepared alkyd resins were air sprayed and applied as thin films on a steel plate to determine the drying times. The set-to-touch times, surface dry times, and 
dry through times were obtained according to ASTM D $1640 .^{33}$ Set-to-touch refers to the non-transferability of the coating upon lightly touching the film with a finger. Dry surface refers to a film that does not adhere to a finger when pressed firmly and does not detach when rubbed slightly. Dry through refers to the non-distortion of the film when a thumb is applied to it in a specified manner and rotated through a $90^{\circ}$ angle. A steel plate with dimensions of $50 \mathrm{~mm} \times 100 \mathrm{~mm} \times 0.1 \mathrm{~mm}$ was coated by spraying the resin (after mixing with driers and the solvent) at $25 \pm 1{ }^{\circ} \mathrm{C}$ and $40 \%$ relative humidity to measure the drying time. The sample was checked using fingertips and filter paper to trace the drying of the film. The film thickness of the tailored nano-surfaces was determined using an Elcometer 345 thickness meter (United Kingdom). The average thickness obtained was $80 \mu \mathrm{m}$.

Impact, cross-cut, pull-off, Mandrel bend, and abrasion tests were performed on the fabricated composite films to evaluate their mechanical and flexibility properties. The flexibility and coating adhesion to the surface were examined based on ISO 6272 using a tubular impact tester (Sheen, UK, model Ref BG5546) to evaluate the damage resistance of the painted composites by abrupt height-weight dropping (1000 g) ${ }^{34}$ The bond strength was formed between the painted film and the applied substrate. The adhesion degrees of the unfilled and filled nanocomposite coatings were investigated using a crosshatch tester with a steel cutter containing $1.5 \mathrm{~mm} \times 6$ teeth (model SH 750, sheen, UK) to form many identical squares (50 to 100). X-cut tape was smoothed on the focal part and pulled, and the adhesion degree was assessed according to ASTM D 3359. ${ }^{35}$ The unfilled and filled SFO-based hyperbranched alkyd nanocomposites were subjected to pull-off tests according to ISO $4624(2014)^{36}$ to determine the adhesion strength of the coating. A hydraulic driven digital tester (Positest AT-M, Ogdensburg, USA) was used with a $20 \mathrm{~mm}$ dolly diameter and cyanoacrylate adhesive. The pull-off strength was recorded for all the specimens, and the coating surface was visually studied. The paint formabilities of the tailored nanocomposites were checked by mandrel bend tests according to ASTM D522. ${ }^{37}$ The bending tester model ref. 809 (sheen, UK) was used, and the mandrel diameter ranged from $3.1 \mathrm{~mm}$ to $38 \mathrm{~mm}$. Abrasion tests were performed using a guide tube onto the painted surface to measure the coating resistance against abrasion caused by an abrasive falling from a specified height. After complete drying at $25 \pm 1{ }^{\circ} \mathrm{C}$, the tests were performed using a 1 $\mathrm{kg} \pm 10 \mathrm{~g}$ load according to ISO 7784-2 (2006). The weights of the coatings were randomly determined after every $250^{\text {th }}$ circle by measuring at least six spots. The decrease in film thickness caused by abrasion was evaluated.

2.7.3. Cytotoxicity tests. Cytotoxicity tests were performed to evaluate the environmental biocompatibility of the prepared nanocomposite by measuring the in vitro cellular response. The cellular toxicity assay was carried out using mouse L929 fibroblast cells and human osteoblast-like MG-63 cells obtained from American Type Culture Collection (ATCC, Manassas, VA, USA). The cells were cultured in contact mode according to the literature. ${ }^{38}$ Culturing was performed in Dulbecco's modified Eagle's medium (DMEM), and the cells were seeded on the nanocomposite films at their exponential phase of growth at a density of $10^{5}$ cells per $\mathrm{cm}^{2}$. The cells were allowed to attach on the surfaces of the films at $37{ }^{\circ} \mathrm{C}$ in an incubation atmosphere containing $5 \% \mathrm{CO}_{2}$ for $3 \mathrm{~h}$. Fresh DMEM medium supplemented with $10 \%$ fetal calf serum (USA) was added to each well, and then the plates were incubated for $24 \mathrm{~h}$ in a humidified atmosphere of $5 \% \mathrm{CO}_{2}$ at $37{ }^{\circ} \mathrm{C}$. Under the same temperature conditions, MTT (1 mg $\mathrm{mL}^{-1}$ ) was added to each well at a strength of $10 \%(\mathrm{v} / \mathrm{v})$, followed by incubation for another $4 \mathrm{~h}$ at $37^{\circ} \mathrm{C}$. The media was removed, followed by the addition of 200 $\mu$ of DMSO. The absorbance was measured using an ELISA plate reader at $570 \mathrm{~nm}$. The resulting absorbance values indicate the quantitative analyses of viable cells in terms of the cell population. Wells that contained cells without treatment were used as controls. Each test was repeated three times for every specimen of the prepared nanocomposites.

2.7.4. Chemical and anticorrosive studies. The chemical resistances of the unfilled and filled SFO-based hyperbranched alkyd resins were tested in water, hydrochloric acid ( $\mathrm{HCl})$, and sodium hydroxide $(\mathrm{NaOH})$. The salt spray test was used to determine the corrosion resistance of the painted panels. The guidelines and test procedures are described in the international standard ASTM B117. ${ }^{39}$ The salt fog solution consists of $\mathrm{NaCl}$ (1 M, 98\%, Merck, India), HCl (1 M, 98\%, Merck, India) and sodium chloride (5 wt\%). The nano-coating surfaces were exposed to a C\&W salt fog cabinet (model SF/MP/AB100, United Kingdom) fitted with a CAC 200/310 concord compressor station (Japan). The salt spray cycle was subdivided as follows: (1) exposure of the tailored nano-coating samples to salt fog at 8 $\mathrm{mL} \min ^{-1}$ (sprinkled by a nozzle for $30 \mathrm{~min}$ ); and (2) a constant cabinet temperature of $35{ }^{\circ} \mathrm{C}$ without salt injection (15 min). The electrolyte was replaced with fresh solution after 1000 hours of exposure.

Water repellency is a major factor that contributes to corrosion protection because it improves the anti-stick characteristics of tailored nano-surfaces toward aqueous particles, leading to high anticorrosion performance. ${ }^{\mathbf{4 0}}$

The contact angles (CA) were determined to express the water repellency properties of the modeled SFO-based hyperbranched alkyd/spherical ZnO nanocomposites. The static CA was evaluated on the cured unfilled and $\mathrm{ZnO}$ filled composites coated on glass specimens using a Krüss $\mathrm{GmbH}$ goniometer (Germany) through the sessile bubble method. The average of at least four measurements was recorded as the CA value.

\section{Results}

\subsection{Structural investigation of SFO-based hyperbranched alkyd paints}

A simple $A_{2}+B_{3}$ methodology was followed using sebacic acid and trimethylolpropane. Scheme 1(A) indicates the polycondensation reaction via this method to prepare hyperbranched polyesters. Scheme 1(B) also indicates the preparation of SFObased hyperbranched alkyd resins through the polycondensation reaction. The as-synthesized SFO-based hyperbranched alkyd polymer and nanocomposites were characterized by several techniques. 
The FT-IR spectra of the as-synthesized hyperbranched polyester (Fig. 1A) indicate characteristic bands at 1736 and $3467 \mathrm{~cm}^{-1}$, which are associated with the stretching frequencies of ester $(\mathrm{C}=\mathrm{O})$ units and $-\mathrm{OH}$ terminals. The FTIR spectra of the SFO-based hyperbranched alkyd polymer resin reflect an intensity reduction in the absorption band of the hydroxyl terminals. The FT-IR spectra of the prepared SFO-based hyperbranched alkyd polymer (Fig. 1A) show reduced intensity of the $\mathrm{OH}$ band, indicating the occurrence of esterification with SFO. The bands observed at 2939 and $2849 \mathrm{~cm}^{-1}$ are attributed to asymmetric and symmetric $\mathrm{CH}_{3}$ stretching, respectively; the bands at 1467 and $1377 \mathrm{~cm}^{-1}$ are assigned to $\mathrm{CH}_{2}$ stretching and bending. The stretching absorption band observed at 3019 $\mathrm{cm}^{-1}$ is attributed to the unconjugated cis-unsaturated bonds in fatty acids. This finding confirms the formation of a highly branched alkyd polymer. The measured acid value $s$ of the prepared SFO-based hyperbranched alkyd resin was correlated with time (Fig. 1B). After curing, this band completely disappeared due to the termination of the surface groups.

Based on the GPC measurements of the prepared hyperbranched polyester, the $M_{\mathrm{w}}$ and PDI are 6542 and 2.685, respectively. After the reaction with $\mathrm{SFO}$, hyperbranched alkyd resins were formed, with a $M_{\mathrm{w}}$ and PDI of 5715 and 2.812, respectively (ESI. Fig. S2 $\dagger$ ). The results indicate an increase in
PDI value, confirming the random dispersion of SFO acids inside the developed polyester.

Manczyk and Szewczyk ${ }^{41}$ reported the synthesis of a highly branched alkyd matrix with a PDI value (1.6) close to that of our prepared SFO-based hyperbranched alkyd resins. This value is lower than the PDI values of commercial alkyd (4.26) and starlike alkyd (4.28) resins. ${ }^{41}$ The ${ }^{1} \mathrm{H}-\mathrm{NMR}$ spectrum of the assynthesized SFO-based hyperbranched alkyd resin is illustrated in Fig. S1. $\dagger$ The signal at $5.41 \mathrm{ppm}$ is due to the $-\mathrm{CH}=$ $\mathrm{CH}-$ protons of SFO linked with HBP polyester; the chemical shift of $\mathrm{CH}_{2} \mathrm{OCOR}$ was observed at $4.27 \mathrm{ppm}$. The chemical shifts observed at 0.7 to $3 \mathrm{ppm}$ are due to the hydrocarbon protons in -methyl, methylene, and methine groups. The chemical shift at $3.5 \mathrm{ppm}$ corresponds to $-\mathrm{CH}_{2}$ directly attached to the hydroxyl terminals. The chemical shift at $5.3 \mathrm{ppm}$ is due to $-\mathrm{CH}=\mathrm{CH}-$, confirming the successful preparation of the SFO-based hyperbranched alkyd matrix from the saturated polyester. The thermal stability and degradation mechanism of the tailored hyperbranched alkyd resin were investigated through TGA measurements. The resin exhibits relative thermal stability at $320{ }^{\circ} \mathrm{C}, 350{ }^{\circ} \mathrm{C}$, and $400{ }^{\circ} \mathrm{C}$, where the weight losses are $10 \%, 20 \%$, and $50 \%$, respectively. The curve of the synthesized SFO-based hyperbranched alkyd exhibits rapid descent with increasing temperature due to decomposition of the resin backbone.
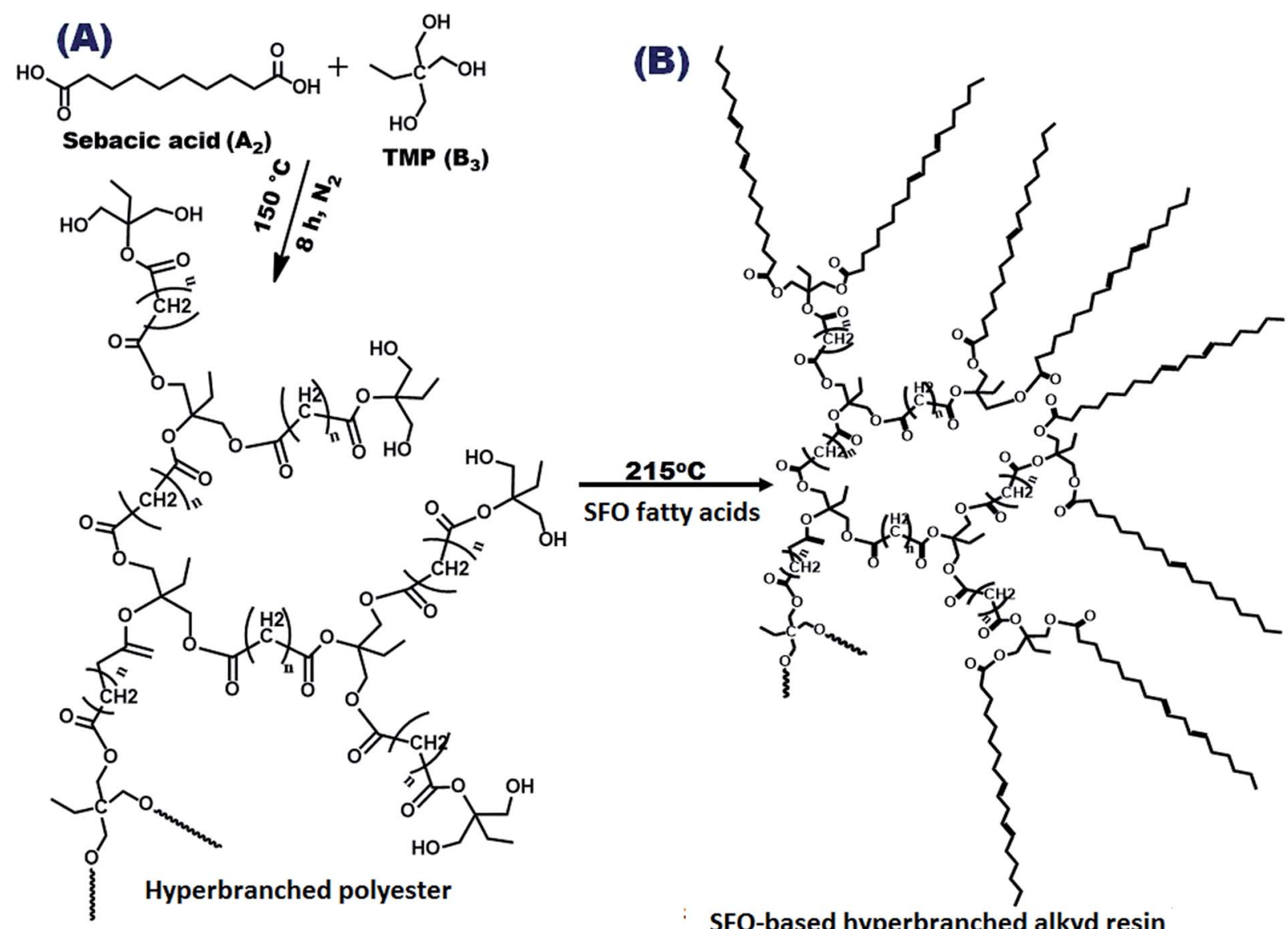

Scheme 1 (A) Synthesis of the hydroxyl-terminated hyperbranched polyester through the $A_{2}+B_{3}$ methodology; (B) schematic of the SFO-based hyperbranched alkyd resin formed from the prepared polyester and SFO. 
A Z Hyperbranched polyester

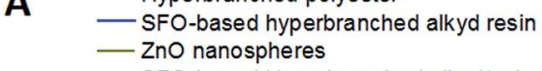

ZnO nanospheres
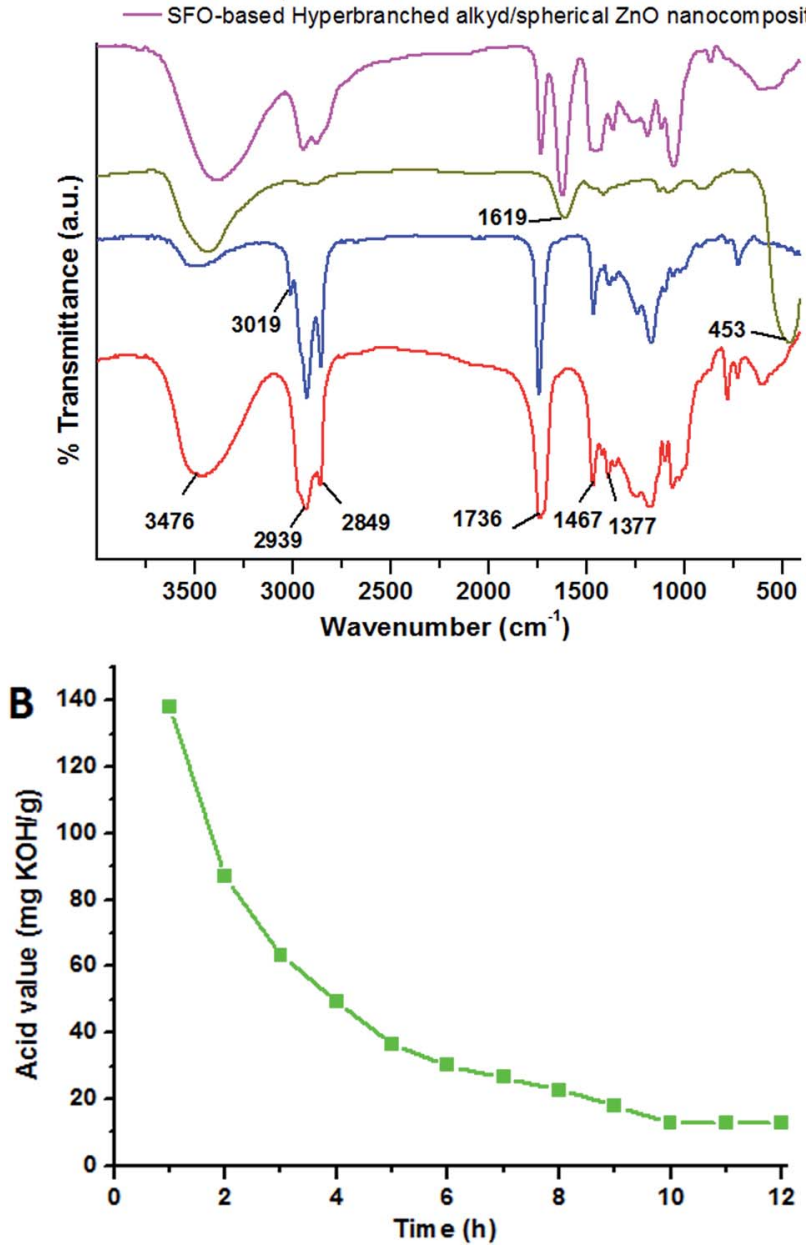

Fig. 1 (A) FT-IR spectra of the as-synthesized hyperbranched polyester SFO-based hyperbranched alkyd resin, ZnO nanospheres, and SFO-based hyperbranched alkyd/spherical nanocomposite; (B) changes in the acid value with time for the prepared SFO-based hyperbranched alkyd resin.

\subsection{Control of size and morphology of ZnO NPs}

A cost-effective and simple technique for preparing ZnO NPs was performed to precisely control their particle diameters and morphologies. The polyol-mediated technique was performed with polyol as solvent and a stabilizing factor to prohibit agglomeration. Nucleation using DEG was enhanced at low PEG concentrations to obtain improved dispersion and small NPs. In the DEG-hydrothermal synthesis technique, the parameters for size and morphology control are dominated by the precursor $\mathrm{Zn}\left(\mathrm{CH}_{3} \mathrm{COOH}\right)_{2}$, whose small diameter and narrow distribution are due to its high molar concentration. The growth of the NPs was restricted using DEG stabilizers. The size and distribution of the NPs could significantly change during preparation, even when minimally altering the parameters. Scheme 2 shows the synthesis mechanism for preparing the spherical ZnO NPs. To analyze the chemical compositions of the prepared materials, FTIR spectra were obtained in the 400 to $4000 \mathrm{~cm}^{-1}$ region (Fig. 1A). The FTIR spectrum revealed that the $\mathrm{Zn}-\mathrm{O}$ linkage band occurred at $453 \mathrm{~cm}^{-1}$, and the peaks at 3415 and 1619 $\mathrm{cm}^{-1}$ corresponded to water absorbed on the $\mathrm{ZnO}$ surface. The crystallinity and morphology characteristics of the prepared ZnO nanospheres were determined from the XRD pattern. The XRD patterns of the as-synthesized ZnO NPs suggest their hexagonal phase (JCPDS 01-075-0576 wurtzite structure) ${ }^{42}$ (Fig. 2A). The characteristic peaks at $2 \theta$ values of $31.67^{\circ}, 34.31^{\circ}$, $36.14^{\circ}, 47.40^{\circ}, 56.52^{\circ}, 62.73^{\circ}$, and $69.03^{\circ}$ are assigned to the $\{100\},\{002\},\{101\},\{102\},\{110\},\{103\}$, and $\{200\}$ inter-planar reflections of the nano-ZnO crystal system, respectively. No impurity peaks were observed, confirming the formation of pure ZnO. The predominant $\{101\}$ crystal facet was confirmed from the peak with the highest intensity. The mean diameter of the nano-Zno particles was calculated by the Scherrer method and was found to be approximately $15 \mathrm{~nm}$ (eqn (2)). ${ }^{43}$

$$
\text { Crystallite size }=K \lambda / \beta_{1 / 2} \cos \theta
$$

where $K$ is the Scherrer constant, and $\theta, \lambda$, and $\beta_{1 / 2}$ are the measured Bragg angle, X-ray wavelength, and line broadening at half the maximum intensity, respectively. In addition, the XRD pattern of the SFO-based hyperbranched alkyd/spherical ZnO nanocomposites shows broad peaks, indicating (i) a low degree of crystallinity and (ii) successful incorporation of spherical nano-ZnO particles in the amorphous hyperbranched alkyd polymer. QLS was used to determine the distribution profile of the as-synthesized NPs. The average diameter is approximately $15 \mathrm{~nm}$, and the polydispersity index is 0.712 , reflecting the poly-disperse nature of the particles (Fig. 2B).

TEM images of the prepared $\mathrm{ZnO}$ particles are presented in Fig. 3A-C. The TEM micrographs of the ZnO NPs showed spherical shapes with an average diameter of $15 \mathrm{~nm}$ and good dispersion of the particles without agglomeration. The polycrystalline nature of the prepared nano-ZnO was confirmed through SAD analysis (Fig. 3D) with indexing of the $\{100\},\{102\}$, and $\{101\}$ crystal planes. Fig. $3 \mathrm{E}$ indicates that the dominant plane is $\{101\}$, and the $d$-spacing is $2.4 \AA$. These findings are similar to the XRD data. The SEM image of nano-ZnO (Fig. 3F) reflects the homogeneity and spherical morphology of the particles as well as their smooth, clean surfaces.

\subsection{Formation of nanocomposite films}

$\mathrm{ZnO}$ nanospheres of various concentrations should be inserted in the polymer matrix to determine the suitable SFO-based hyperbranched alkyd/spherical ZnO nanocomposites for corrosion protection. Scheme 3 shows the detailed synthesis process of the nanocomposites. Different drier percentages were utilized for film formation of the alkyd unfilled and filled composites. Steel samples were used as surfaces on which the SFO-based hyperbranched alkyd/spherical ZnO nanocomposites were applied. The samples were dried at R.T. for $72 \mathrm{~h}$ (air dried). All the specimens possess an average film thickness of $60 \mu \mathrm{m}$ and excellent adhesion characteristics. The unfilled films have a transparent and homogenous nature. However, the transparent nature of the filled nanocomposites gradually decreases with increasing nano-ZnO filler percentage. At high nanofiller concentrations, the color intensity increased in the nano-coatings. 


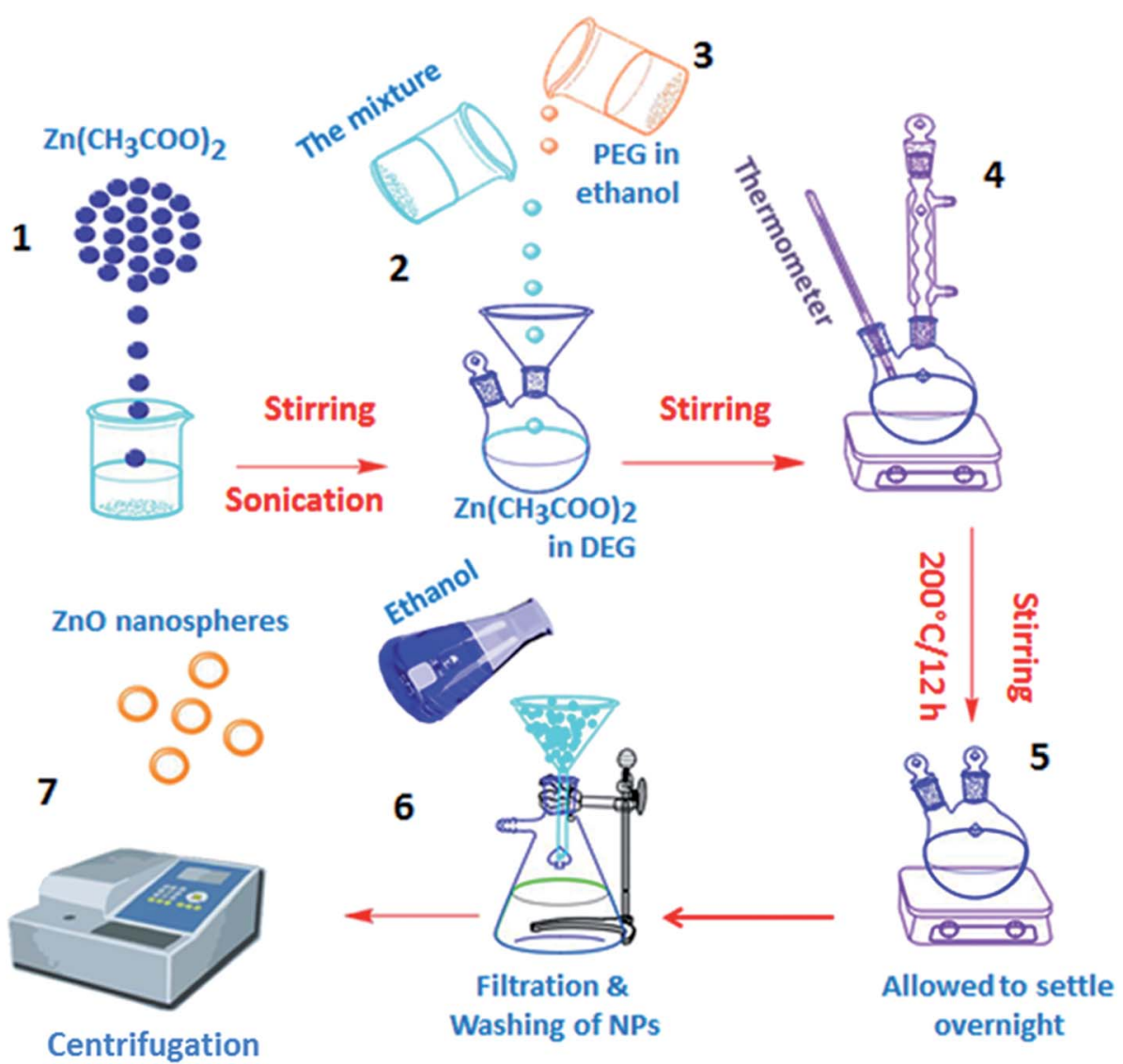

Scheme 2 Preparation of $\mathrm{ZnO}$ nanospheres through a precipitation technique using DEG and PEG as stabilizers, chelating agents and limiting agents for NP growth.

The FTIR spectrum of the cured SFO-based hyperbranched alkyd/spherical ZnO nanocomposite reveals complete disappearance of the absorption band at $3019 \mathrm{~cm}^{-1}$. This finding indicated the unsaturation caused by SFO fatty acids and proved the film curing to be successful (Fig. 1A). The TEM images of the as-synthesized SFO-based hyperbranched alkyd/spherical ZnO nanocomposites (0.5\% nanofiller\%) present well-dispersed NPs inside the matrix without any aggregation (ESI, Fig. S3A and B $\uparrow$ ). The retention of the well-dispersed $\mathrm{ZnO}$ nanospheres in the homogenous domains inside the alkyd matrix improved the physical, chemical, and anticorrosive features of the nanocomposites. At high nanofiller percentages ( $1 \%$ to $5 \% \mathrm{ZnO}$ nanospheres), unwanted clustering of the $\mathrm{ZnO}$ nanospheres was observed (ESI, Fig. S3C and D†), thereby reducing the thickness of the particle-matrix surface layer and diminishing the surface characteristics.

\subsection{Nanocomposite surface properties}

The $\mathrm{ZnO}$ nanospheres affected the thermal behavior of the modeled nano-films. Variations in the thermal stability of the unfilled and filled SFO-based hyperbranched alkyd nanocomposites were evaluated by determining the initial degradation temperature and the temperature at which maximum weight loss was observed; these parameters are expressed as $T_{\mathrm{i}}$ and $T_{\max }$, respectively. For the unfilled SFO-based hyperbranched cured alkyd film, the $T_{\mathrm{i}}$ is $297{ }^{\circ} \mathrm{C}$, which may be due to the decrosslinking action, and the $T_{\max }$ is $448{ }^{\circ} \mathrm{C}$, which may be due to the decomposition of ester, ether, and unsaturated bonds. The ZnO nanospheres were well dispersed when the nanofiller loading reached $0.5 \%$ and exhibited higher $T_{\mathrm{i}}$ and $T_{\max }$ values than the virgin polymer film. Moreover, agglomeration and particle clustering occurred when loading $1 \%$ to $5 \%$ nanofillers, resulting in decreased $T_{\mathrm{i}}$ and $T_{\max }$ (Table S1 $\dagger$ ). The recorded values indicate the physico-mechanical interaction between the alkyd resin and ZnO nanofillers. The agglomerated nanofillers can enter the nanocomposite channels, increase particle-particle interaction and reduce the physico-mechanical characteristics. The incorporation of $\mathrm{ZnO}$ nanospheres up to $0.5 \%$ increases the thermal stability due to the polymer matrix-nano-ZnO (with a large surface area) interaction, forming stable nanocomposites. At higher nanofiller concentrations, the polymer-filler interaction decreases, the particle-particle interaction increases, and the NPs condense with each other.

\subsection{Contact angle measurements}

Non-wettability is a major parameter that prevents sticking of aqueous corrosive molecules to a tailored surface. ${ }^{44}$ Water repellency is a good anticorrosive characteristic for coating surfaces. ${ }^{40,44}$ Yang et al.$^{40}$ synthesized a hydrophobic multilayer coating of Al-N/ $\mathrm{Cr}-\mathrm{N}$ for corrosion resistance. Static contact angle measurements 

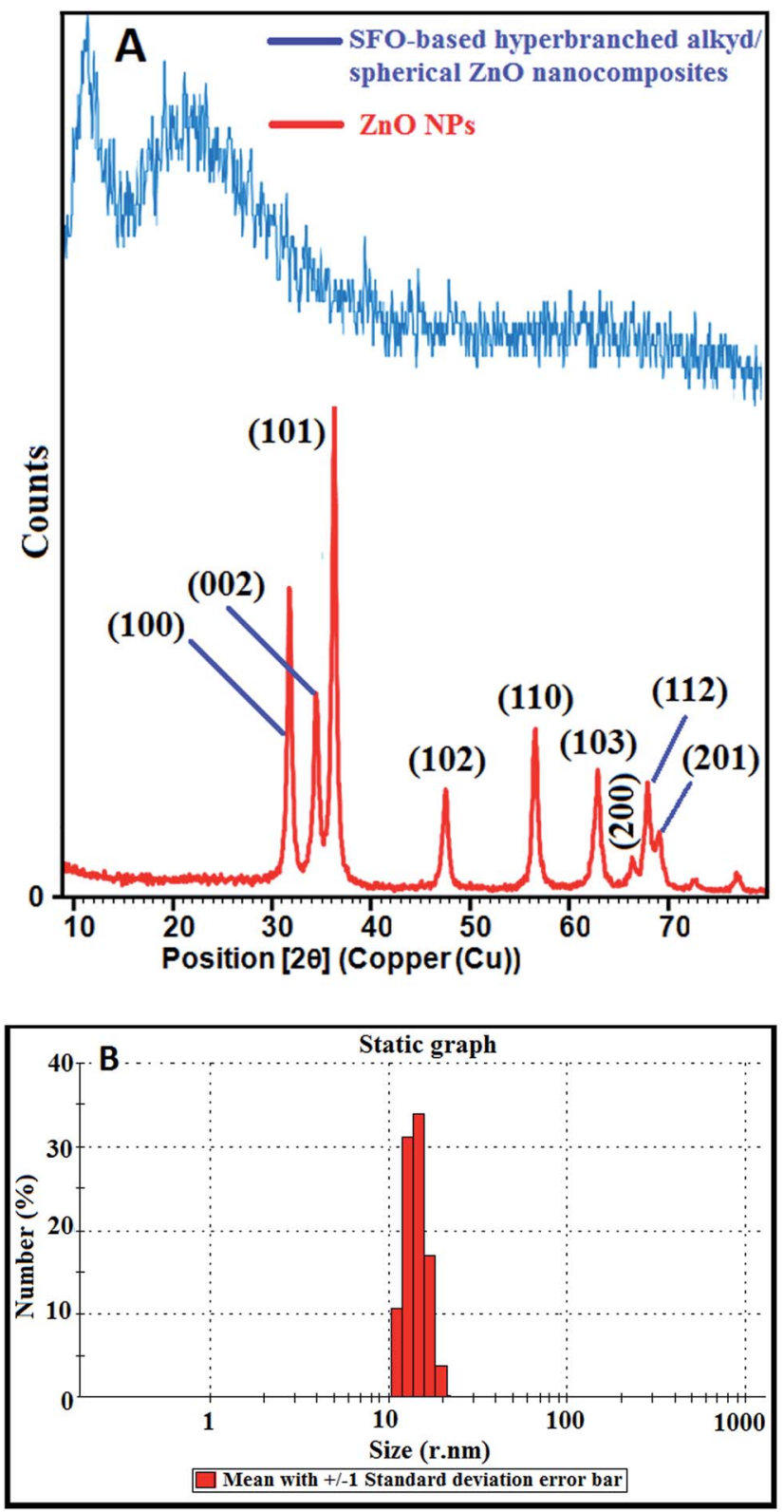

Fig. 2 (A) XRD patterns of the prepared spherical nano-ZnO particles and SFO-based hyperbranched alkyd/spherical ZnO nanocomposite; (B) QLS of the as-synthesized spherical ZnO nanofillers.

were performed for the unfilled and filled SFO-based hyperbranched alkyd/spherical ZnO nanocomposites (Fig. 4). The cured virgin resin exhibits a contact angle higher than $90^{\circ}$ and hydrophobicity, which increases with increased percentage of nanofiller loading. The optimum hydrophobicity was obtained for $0.5 \%$ $\left(106^{\circ}\right)$ due to the good dispersion of the hydrophobic nanofillers. The CA decreased because of agglomerations at high concentrations ( $1 \%$ to $5 \%$ ) (from 103 to 92 ). Thus, the tailored coatings were confirmed to be water repellent.

\subsection{Mechanical feature tests}

Coating materials should exhibit superior properties, such as excellent adhesion to the substrate, to be used for corrosion protection. In this study, the prepared unfilled and filled nanosurfaces exerted excellent adhesion and flexibility performance. Impact resistance is the ability to withstand shock loading over a specimen and absorb energy during collision. This parameter depends on the polymer structure and free volume available among the backbone chains. The results indicate the extreme flexibility of the tested specimens and the absence of film cracking under $100 \mathrm{~cm}$ height and $1800 \mathrm{~g}$ weight. All the specimens possess impact resistances higher than $18 \mathrm{~J}$, which is the upper limit of the available potential energy (Table 1). This finding may be attributed to the flexible nature of the films due to their long-chain fatty acids, resulting in available free volume between adjacent chains. A facile cross-hatch experiment (pass/fail test) was performed on model nano-coating systems. The results indicate no visible adhesion defects (Table 1). The pull-off test was performed to measure the lowest tension strength required to rupture the coated surfaces. A dolly was secured in a vertical direction to the designed nano-paints using an adhesive material. The analytical device was bonded to the dolly, and the pull-off test was performed by increasing the force applied to the virgin and nano-ZnO composites. The results are shown in Fig. 5. The test measurements were different for the different concentrations of nanofiller loadings. The highest pull-off value is that of the specimen with $0.5 \%$ nanofiller, and the values decrease as the nanofiller loading increases from $1 \%$ to $5 \%$. The low values for high nanofiller loadings are related to the fracturability caused by the aggregation and agglomeration of NPs, which increases the particle-particle interactions and decreases the surface areas of the NPs and the bonding force between the SFO-based hyperbranched alkyd matrix and the steel surface. All the nano-ZnO composites exhibited higher mechanical and adhesion performance compared with the virgin resin, indicating that adding $\mathrm{ZnO}$ nanospheres improved the mechanical and adhesion performance of the resin. Excellent pull-off test values were also observed for the well-distributed nanospheres $(0.5 \% \mathrm{ZnO})$ in the SFO-based hyperbranched alkyd matrix, confirming the structure-property relationship. Mandrel bending experiments were also conducted. Film cracks or intrusions were not detected in any samples. The assessments were performed after bending the coating films to a tubular axle lower than $5 \mathrm{~mm}$ (Table 1). The T-bend test was conducted on all samples without visible cracking. No intrusion was detected under a magnifying glass in any of the investigated coatings after penetration and bending on a $<5 \mathrm{~mm}$ cylindrical spindle (Table 1 ). The abrasion resistance of the unfilled SFO-based hyperbranched alkyd film and filled SFO-based hyperbranched alkyd/spherical ZnO nanocomposites was determined by increasing the cycle number and measuring the weight loss (Fig. 6). The abrasion resistance increases with increasing nanofiller loading up to $0.5 \%$ due to the good dispersion of the nanofillers, which improves the mechanical properties. At high nanofiller concentrations, the occurrence of agglomeration may reduce the mechanical properties and abrasion resistance.

\subsection{In vitro toxicity of the nanocomposites}

The SFO-based hyperbranched alkyd/spherical ZnO nanocomposites were subjected to cytotoxic studies with murine 


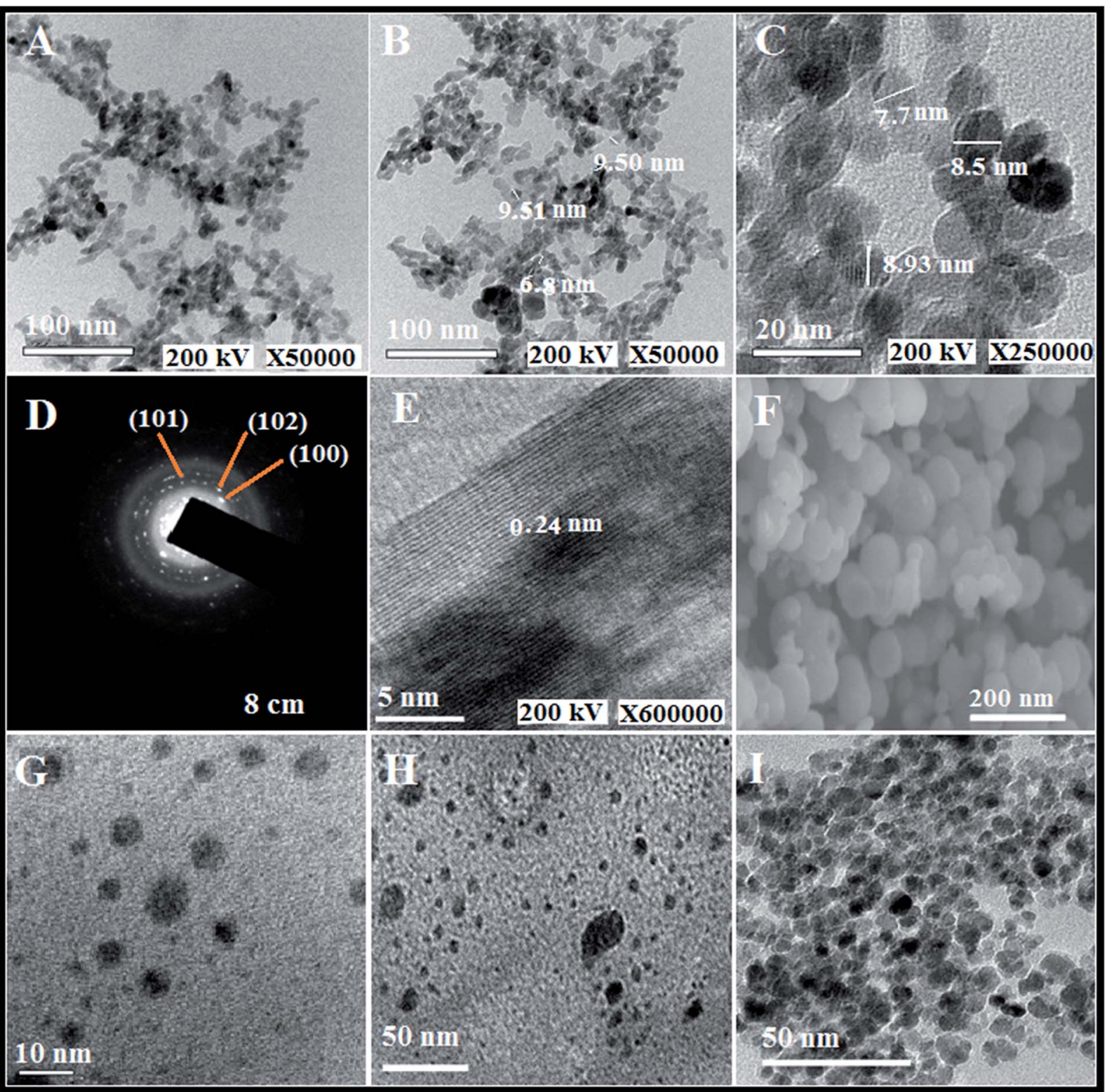

Fig. 3 (A)-(C) TEM images of the synthesized spherical ZnO NPs at different magnifications; (D) corresponding SAD patterns of the prepared $\mathrm{ZnO}$ nanospheres; (E) corresponding crystal lattice, which is consistent with the XRD results; (F) corresponding FE-SEM images of the prepared $\mathrm{ZnO}$ nanospheres; $(\mathrm{G})$ and $(\mathrm{H})$ corresponding TEM images of the prepared SFO-based hyperbranched alkyd/ZnO nanocomposites at a low concentration (0.5\% nanofillers); (I) TEM image of the prepared SFO-based hyperbranched alkyd/spherical ZnO nanocomposites at a high concentration (5\% nanofillers).

fibroblast L929 and human osteoblast-like MG-63 cells (Fig. 7). The cellular toxicity of the fabricated nanocomposites was evaluated using the MTT assay after $24 \mathrm{~h}$. The MTT assay results revealed the non-toxic nature of the prepared nanocomposites on the cell lines even at higher nanofiller concentrations compared with the unfilled SFO-based hyperbranched alkyd. The significant biocompatibility of the prepared nanocomposites was obtained without disrupting the cellular machinery over the surface, indicating excellent in vitro cytocompatibility. Our findings also show that the most eco-friendly nanocomposite was that with well-distributed NPs $(0.5 \%)$ because of the increased hydrophobicity. These comparative results suggested that SFO-based hyperbranched alkyd/ spherical $\mathrm{ZnO}$ nanocomposites are a promising candidate for eco-friendly applications.

\subsection{Chemical and anticorrosive resistance}

The chemical resistances of the SFO-based hyperbranched alkyd cured film and nanocomposites were assessed against different solutions, such as $\mathrm{NaCl}, \mathrm{H}_{2} \mathrm{O}$, and $\mathrm{HCl}$ (Table 2). The tailored films exhibit superior properties and high stability toward these solutions. The chemical resistance results of these films and nanocomposites against $\mathrm{NaOH}$ reflect low stability. The stabilities of all the nanocomposites were higher than that 


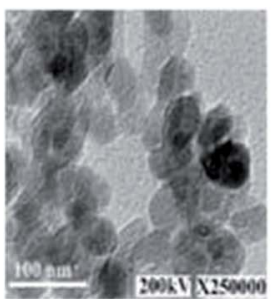

Nano-ZnO spheres
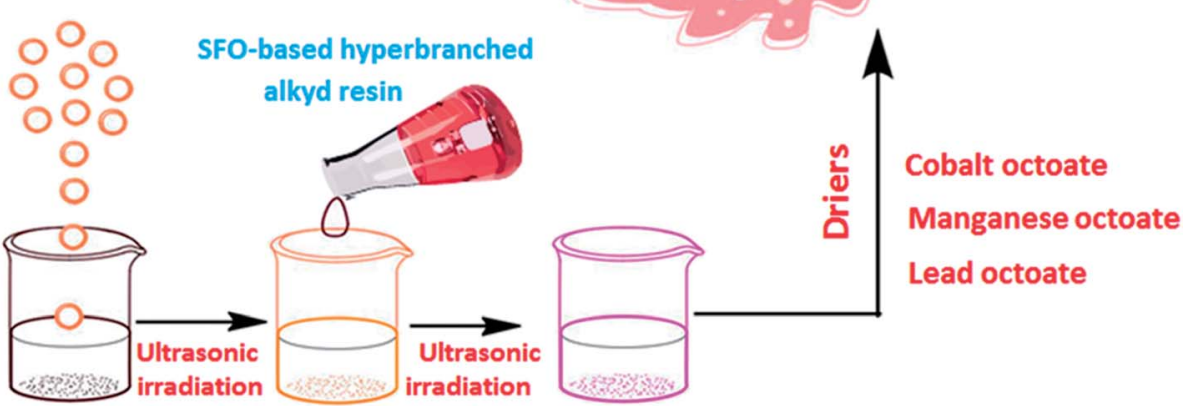

Scheme 3 Preparation of a series of hyperbranched alkyd/ZnO nanocomposites by adding various nanofiller concentrations to the prepared $\mathrm{SFO}$-based hyperbranched alkyd resin.

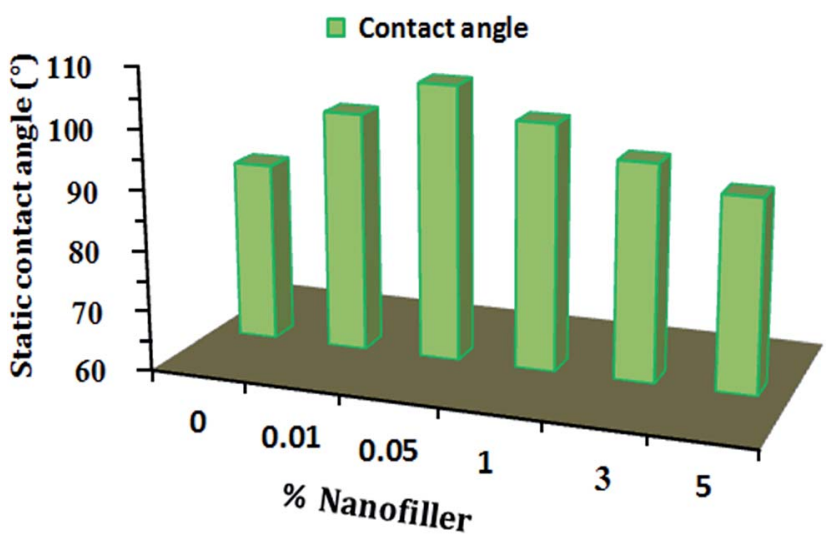

Fig. 4 Water contact angle measurements of the as-synthesized cured virgin and filled SFO-based hyperbranched alkyd/spherical ZnO nanocomposites (error bars represent \pm 1 standard deviations based on three determinations).

Table 1 Mechanical properties of the prepared unfilled and filled SFObased hyperbranched alkyd/spherical ZnO nanocomposites with different nanofiller concentrations

Concentration of $\mathrm{ZnO}$ nanofillers in the prepared SFO-based hyperbranched alkyd nanocoating

\begin{tabular}{lllllll}
\hline Property & $0.0 \%$ & $0.10 \%$ & $0.50 \%$ & $1.0 \%$ & $3.0 \%$ & $5.0 \%$ \\
\hline $\begin{array}{l}\text { Impact resistance } \\
\text { (joules) }\end{array}$ & $>18$ & $>18$ & $>18$ & $>18$ & $>18$ & $>18$ \\
$\begin{array}{l}\text { Cross-hatch } \\
\text { T-Bending }\end{array}$ & $\begin{array}{l}\text { Pass } \\
<5\end{array}$ & $\begin{array}{l}\text { Pass } \\
<5\end{array}$ & $\begin{array}{l}\text { Pass } \\
<5\end{array}$ & $\begin{array}{l}\text { Pass } \\
<5\end{array}$ & $\begin{array}{l}\text { Pass } \\
<5\end{array}$ & $\begin{array}{l}\text { Pass } \\
>5\end{array}$
\end{tabular}

of the unfilled cured SFO-based hyperbranched alkyd resin. The stability and chemical resistance were found to be associated with the nanofiller percentage of the SFO-based hyperbranched alkyd/spherical ZnO nanocomposites in the following sequence: $0.1 \%$ nanofillers $<0.5 \%$ nanofillers $>1 \%$ nanofillers $>3 \%$ nanofillers $>5 \%$ nanofillers. These results can be attributed to the enhanced crosslinking degree due to nanofiller distribution in the curing mechanism, which afforded the extraordinary protecting effect of - $\mathrm{COO}$ groups against water molecules (which may cause corrosion). Previous studies confirmed that hyperbranched alkyd matrices demonstrate greater anticorrosive protection than conventional matrices. ${ }^{45}$ Ikhuoria et al. ${ }^{46}$ reported the preparation of a conventional alkyd matrix with

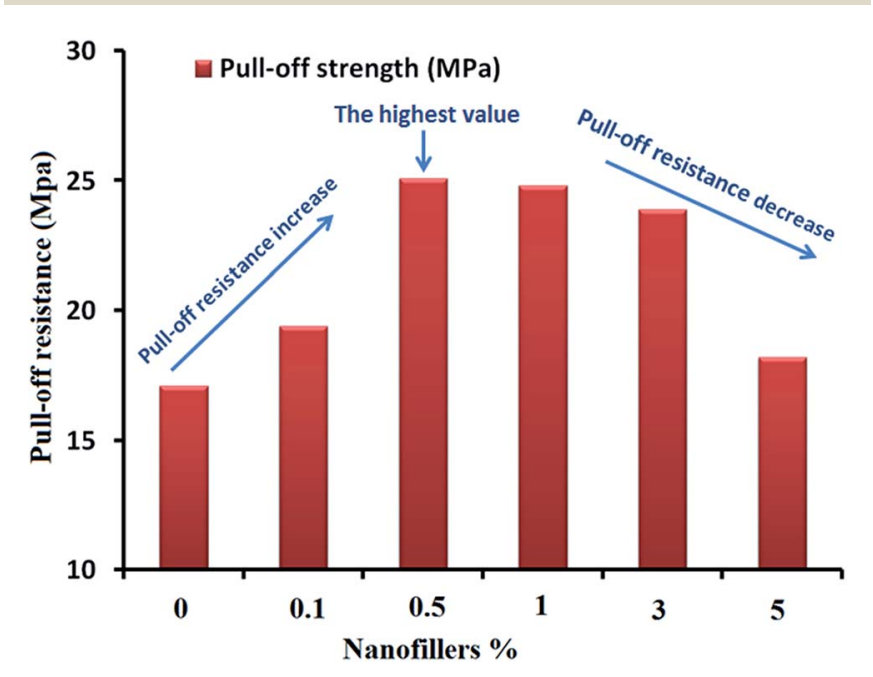

Fig. 5 Pull-off test measurements of unfilled and filled SFO-based hyperbranched alkyd/ZnO nanocomposites (error bars represent \pm 0.25 standard deviations based on three replications). 


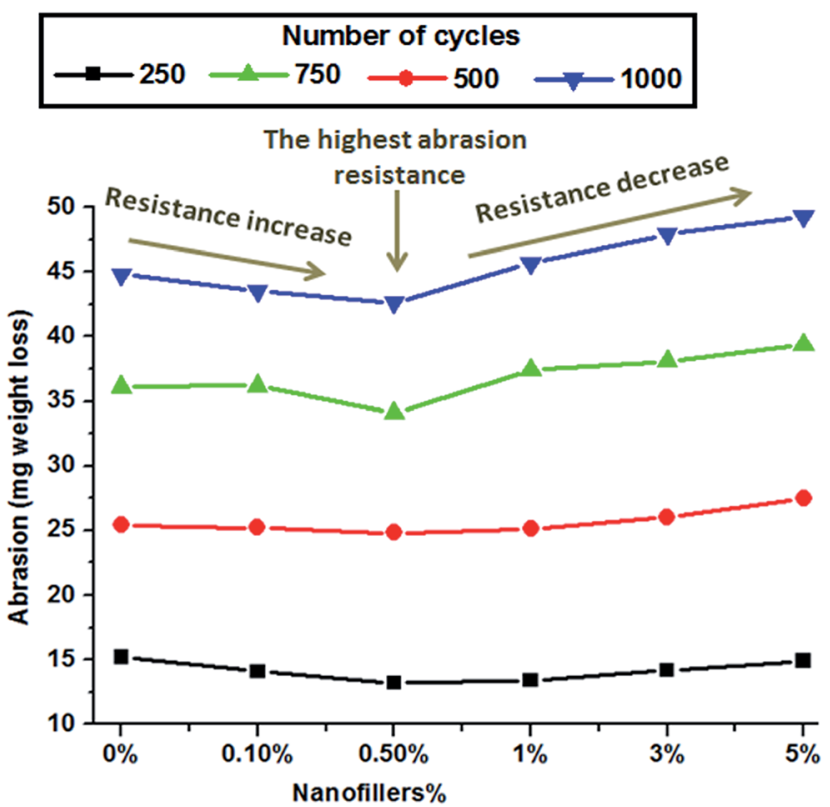

Fig. 6 Abrasion tests (mg loss) of unfilled and filled SFO-based hyperbranched alkyd/spherical $\mathrm{ZnO}$ nanocomposites (error bars represent \pm 1 standard deviations based on three measurements).

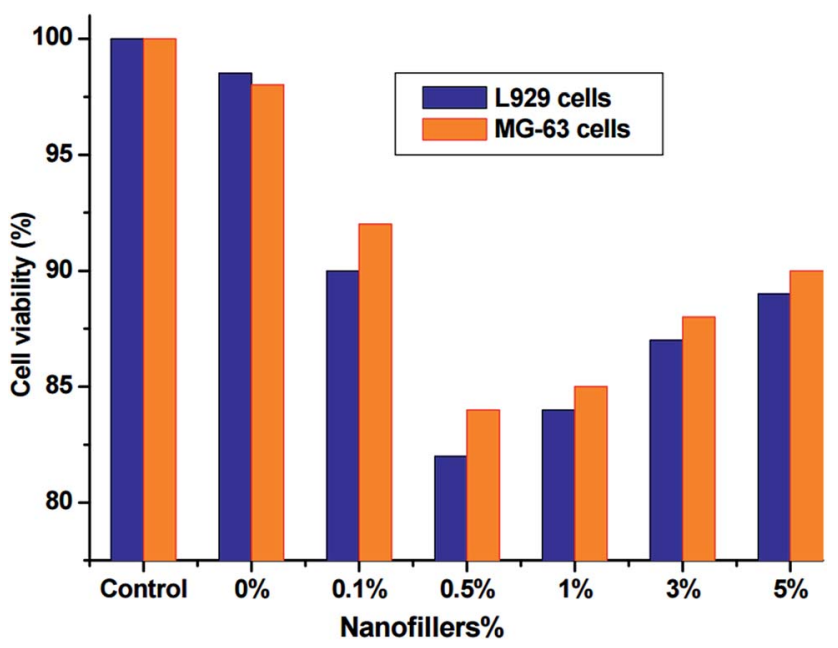

Fig. 7 Cellular toxicities of the prepared unfilled and hyperbranched alkyd nanocomposites determined by MTT assay on L929 cells and MG- 63 cells (error bars represent \pm 0.05 standard deviations based on three measurements). reduced immunity against $\mathrm{NaOH}$ solution, wherein the prepared coating layers were completely dissociated.

The anticorrosive behavior of the designed virgin and SFObased hyperbranched alkyd/spherical $\mathrm{ZnO}$ nanocomposites was estimated by the salt fog technique. The corrosion distribution over the painted surface was assessed by creating an Xcut in the tailored film. Test panels of the unfilled and filled nanocomposites were examined after 250 and 500 hours of immersion in a salt spray cabinet. For the unfilled SFO-based hyperbranched alkyd film, the corrosion spread was approximately 1.5 to $2 \mathrm{~mm}$; in the case of $0.5 \%$ and $1 \% \mathrm{ZnO}$ doped in the SFO-based hyperbranched alkyd matrix, the spreads were nearly 0.9 and $1.2 \mathrm{~mm}$, respectively. This finding reflects the effects of the distribution of the spherical $\mathrm{ZnO}$ nanofillers on corrosion protection. The gradual insertion of nano-ZnO fillers decreases the density of blisters and the rusting of spots up to a concentration of $0.5 \%$ nano-ZnO particles due to the good distribution of the nanofillers, the improved adhesion to the substrate and the water repellency to water molecules. With increasing nano-ZnO filler concentrations (1\%, 3\%, and 5\%), the water permeability increased gradually and the number of corrosion spots increased. These features could be due to aggregation of the as-synthesized nano-ZnO and a reduction in the nano-surface area and adhesion strength with the substrate.

\section{Conclusion}

We developed a SFO-based hyperbranched alkyd resin that appears to be an excellent candidate for modern VOC-free composites for the first time. The good performance of our advanced nanocomposites was based on features such as high branching degree, low viscosity, low molecular weight, and abundant surface functional groups. For example, we used welldispersed $\mathrm{ZnO}$ nanospheres (with an average diameter of 15 $\mathrm{nm}$ ) that were fabricated via a facile and inexpensive technique as nanofillers for the fabrication of the nanocomposites. To demonstrate the effectiveness of the $\mathrm{ZnO}$ nanospheres, a set of innovative films of micro-nano SFO-based hyperbranched alkyd/spherical $\mathrm{ZnO}$ nanocomposites was prepared using different nanofiller concentrations. Our findings show that the nanofiller concentrations are essential to establish synergetic effects on the performance of the films at the micro-nano binary scale. Furthermore, their physical and mechanical characteristics, including water-repellency, cellular cytotoxicity, anticorrosive characteristics, impact, bending, crosshatch, salt

Table 2 Chemical resistance of the prepared unfilled and filled SFO-based hyperbranched alkyd/spherical ZnO nanocomposites ${ }^{a}$

\begin{tabular}{|c|c|c|c|c|}
\hline Cured film (nanofiller\%) & $\mathrm{H}_{2} \mathrm{O}$ & $\mathrm{HCl}(0.1 \mathrm{M})$ & $\mathrm{NaOH}(0.1 \mathrm{M})$ & $\mathrm{NaCl}(5 \%)$ \\
\hline SFO-based hyperbranched alkyd film & A & A & $\mathrm{C}$ & A \\
\hline SFO-based hyperbranched alkyd/spherical ZnO nanocomposite ( $0.1 \%$ nanofillers) & A & A & $\mathrm{C}$ & A \\
\hline SFO-based hyperbranched alkyd/spherical ZnO nanocomposite ( $1 \%$ nanofillers) & A & A & $\mathrm{B}$ & A \\
\hline SFO-based hyperbranched alkyd/spherical ZnO nanocomposite (3\% nanofillers) & A & A & $\mathrm{C}$ & A \\
\hline SFO-based hyperbranched alkyd/spherical ZnO nanocomposite (5\% nanofillers) & A & A & $\mathrm{C}$ & A \\
\hline
\end{tabular}

${ }^{a}$ A: not removed; B: partially removed; C: totally removed. 
spray, abrasion, and stability, were intensively studied. Both the unfilled and filled SFO-based hyperbranched alkyd films and nanocomposites show good adhesion, bending, impact, ductility, and high anticorrosive resistance. Our results revealed that the film loaded with $0.5 \% \mathrm{ZnO}$ as the nanofiller showed significant improvements in its anticorrosive, chemical, surface, and mechanical performance. With high filling percentages ( $1 \%$ to $5 \%$ ), the agglomeration of the NPs and the formation of non-homogeneous surfaces decreased the hydrophobicity of the nanocomposites, leading to physical, mechanical and anticorrosive features. As a result, the coating artifacts of the nanofiller, such as well-dispersed NPs, spherical morphology, specific $15 \mathrm{~nm}$ particles, and rational added amount of $\mathrm{ZnO}$ nanofillers (i.e., $0.5 \%$ ) are the key components that increase the anticorrosive performance and durability of the film nanocomposites. For environmental chemistry, the tailored nanocomposites demonstrate the merits of long life, easy preparation, low cost, and eco-friendliness. Thus, our nanocomposite design may address the global environmental concerns caused by outdated chemical technologies.

\section{Notes and references}

1 (a) A. Hofland, Prog. Org. Coat., 2012, 73, 274-282; (b) H. Liebscher, Prog. Org. Coat., 2000, 40, 75-83.

2 P. P. Vallejo, B. L. López and E. A. Murillo, Prog. Org. Coat., 2015, 87, 213-221.

3 S. Haseebuddin, R. Parmar, G. Waghoo and S. K. Ghosh, Prog. Org. Coat., 2009, 64, 446-453.

4 S. Haseebuddin, R. Parmar, G. Waghoo and S. K. Ghosh, Prog. Org. Coat., 2009, 64, 446-453.

$5 \mathrm{~V}$. Atimuttigul, S. Damrongsakkul and W. Tanthapanichakoon, Korean J. Chem. Eng., 2006, 23, 672-677.

6 C. Karakaya, G. Gündüz, L. Aras and I. A. Mecidoglu, Prog. Org. Coat., 2007, 59, 265-327.

7 (a) N. E. Ikladious, S. H. Mansour, J. N. Asaad, H. S. Emira and M. Hilt, Prog. Org. Coat., 2015, 89, 252-259; (b) N. E. Ikladious, J. N. Asaad, H. S. Emira and S. H. Mansour, Prog. Org. Coat., 2017, 102, 217-224.

8 E. A. Murillo, P. P. Vallejo and B. L. López, Prog. Org. Coat., 2010, 69, 235-240.

9 (a) K. Manczyk and P. Szewczyk, Prog. Org. Coat., 2002, 44, 99-109; (b) A. M. Elsaid, M. M. Badr and M. S. Selim, World Academy of Science, Engineering and Technology, 2013, vol. 80, pp. 230-236.

10 (a) B. Voit, D. Beyerlein, K.-J. Eichhorn, K. Grundke, D. Schmaljohann and T. Loontjens, Chem. Eng. Technol, 2002, 25, 704-707; (b) A. F. Ghanem, A. El-Gendi, M. H. Abdel Rehim and K. M. El-Khatib, RSC Adv., 2016, 6, 32245-32257; (c) V. Somisetti, S. Allauddin, R. Narayan and K. V. S. N. Raju, $R S C A d v$., 2015, 5, 74003-74011.

11 (a) C. Gao and D. Yan, Prog. Polym. Sci., 2004, 29, 183-275; (b) B. R. Frings and M. Wend, New Hyperbranched Polyesters for UV-Curing, DIC Technical Review, 2003, vol. 9, pp. 43-51.

12 T. Zhang, B. A. Howell, A. Dumitrascu, S. J. Martin and P. B. Smith, Polymer, 2014, 55, 5065-5072.
13 K. Johansson, T. Bergman and M. Johansson, ACS Appl. Mater. Interfaces, 2009, 1, 211-217.

14 P. P. Chiplunkar and A. P. Pratap, Prog. Org. Coat., 2016, 93, 61-67.

15 F. A. El-Hai, I. Sabbah and N. A. Abdel-Rehim, Int. J. Polym. Mater., 2004, 53, 871-878.

16 (a) A. Gandini, T. M. Lacerda, A. J. F. Carvalho and E. Trovatti, Chem. Rev., 2016, 116(3), 1637-1669; (b) E. A. Murillo, B. L. López and W. Brostow, J. Appl. Polym. Sci., 2012, 124, 3591-3599.

17 D. Iseri-Caglar, E. Bastürk, B. Oktay and M. V. Kahraman, Prog. Org. Coat., 2014, 77, 81-86.

18 E. A. Murillo, P. P. Vallejo and B. L. López, J. Appl. Polym. Sci., 2011, 120, 3151-3158.

19 A. I. Aigbodion and C. K. Pillai, J. Appl. Polym. Sci., 2001, 79, 2431-2438.

20 (a) M. S. Selim, S. A. El-Safty, M. A. El-Sockary, A. I. Hashem, O. M. Abo Elenien, A. M. EL-Saeed and N. F. Fatthallah, Mater. Des., 2016, 101, 218-225; (b) M. S. Selim, S. A. ElSockary, M. A. El-Sockary, A. I. Hashem, O. M. Abo Elenien, A. M. EL-Saeed and N. A. Fatthallah, Data Brief, 2016, 8, 1357-1364.

21 (a) M. S. Selim, S. A. El-Safty, M. A. El-Sockary, A. I. Hashem, O. M. Abo Elenien, A. M. EL-Saeed and N. A. Fatthallah, RSC Adv., 2015, 5, 63175-63185; (b) D. Hassen, S. A. El-Safty, K. Tsuchiya, A. Chatterjee, A. Elmarakbi, M. A. Shenashen and M. Sakai, Sci. Rep., 2016, 6, 24330.

22 (a) O. Rahman and S. Ahmad, RSC Adv., 2014, 4, 14936; (b) H. R. Ong, M. M. R. Khan, R. Ramli, M. W. Rahman and R. M. Yunus, $R S C A d v$., 2015, 5, 95894-95902.

23 S. K. Dhoke and A. Khanna, Mater. Chem. Phys., 2009, 117, 550-556.

24 (a) L. Bistricic, V. Borjanovic, L. Mikac and V. Dananic, Vib. Spectrosc., 2013, 68, 1-10; (b) T. Y. Suman, S. R. Radhika Rajasree and R. Kirubagaran, Ecotoxicol. Environ. Saf., 2015, 113, 23-30.

25 (a) M. S. Selim, S. A. El-Sockary, M. A. El-Sockary, A. I. Hashem, O. M. Abo Elenien, A. M. EL-Saeed and N. A. Fatthallah, $R S C$ Adv., 2015, 5(26), 19933-19943; (b) D. Hassen, M. A. Shenashen, S. A. El-Safty, M. M. Selim, H. Isago, A. Elmarakbi, A. El-Safty and H. Yamaguchi, $J$. Power Sources, 2016, 330, 292-303; (c) M. A. Shenashen, D. Hassen, S. A. El-Safty, N. Akhtar, A. Chatterjee and A. Elmarakbi, Adv. Mater. Interfaces, 2016, 3(24), 1600743.

26 (a) C. F. Klingshirn, B. K. Meyer, A. Waag, A. Hoffmann and J. Geurts, Zinc oxide from fundamental properties towards novel applications, Springer-Verlag, Berlin, Heidelberg, 2010; (b) L. V. Ana Stanković, S. Marković, S. Dimitrijević, S. D. Skapin and D. Uskokovic, in Tenth Young Researchers' Conference-Materials Science and Engineering, Belgrade, Serbia, 21-23 December 2011, Institute of Technical Sciences of SASA, Belgrade, 2011, p. 62.

27 (a) M. A. Shenashen, D. Hassen, S. A. El-Safty, H. Isago, A. Elmarakbi and H. Yamaguchi, Chem. Eng. J., 2017, 313, 83-98; (b) W. Warkocki, S. A. El-Safty, M. A. Shenashen, E. Elshehy, H. Yamaguchia and N. Akhtar, J. Mater. Chem. A, 2015, 3, 17578-17589. 
28 A. Sirelkhatim, S. Mahmud, A. Seeni, N. H. M. Kaus, L. C. Ann, S. K. M. Bakhori, H. Hasan and D. Mohamad, Nano-Micro Lett., 2015, 7(3), 219-242.

29 J. Alam, U. Riaz, S. Ashraf and S. Ahmad, J. Coat. Technol. Res., 2008, 5, 123-128.

30 J. Zhai, X. Tao, Y. Pu, X.-F. Zeng and J.-F. Chen, Appl. Surf. Sci., 2010, 257, 393-397.

31 (a) C. Yang, Q. Li, L. Tang, K. Xin, A. Bai and Y. Yu, Appl. Surf. Sci., 2015, 357, 1928-1938; (b) A. P. Singh, G. Gunasekaran, C. Suryanarayana and R. B. Naik, Prog. Org. Coat., 2015, 87, 95-105.

32 (a) R. Mesias and E. A. Murillo, J. Appl. Polym. Sci., 2015, 132, 41589; (b) H. Nosal, J. Nowicki, M. Warzala, I. Semeniuk and E. Sabura, Prog. Org. Coat., 2016, 101, 553-568.

33 (a) ASTM D1640, Standard test method fordrying, curing, or film formation of organic coatings at room temperature, Annual Book of ASTM Standards, American Society for Testing and Materials, Philadelphia, PA, 1997, vol. 6.01; (b) C. F. Uzoh, O. F. Mbonu and O. D. Onukwuli, Prog. Org. Coat., 2016, 101, 71-80.

34 EN ISO 6272-1, Paints and varnishes-Rapid-Deformation (impact resistance) tests - Part1, Falling-Weight Test, LargeArea Indenter, CEN, Brussels, Belgium, 2002.

35 ASTM-D3359-02, Standard Test Methods for measuring (ASTM) Adhesion by Tape Test, Philadelphia, PA, USA, 2002.
36 ISO 4624:2002 Paints, Varnishes and plastics. Pull-Off test for adhesion.

37 ASTM D522, Standard Method for Manderal Bend Test of Attached Organic Coatings, American Society for Testing and Materials, Philadelphia, 1988.

38 T. Mosmann, J. Immunol. Methods, 1983, 65(1-2), 55-63.

39 ASTM B117, Standard Method of Salt Spray (Fog) Testing, American Society for Testing and Materials, Philadelphia, 1990.

40 Y. S. Yang, T. P. Cho and Y. C. Lin, Surf. Coat. Technol., 2014, 259, 172-177.

41 K. Manczyk and P. Szewczyk, Prog. Org. Coat., 2002, 44(2), 99-109.

42 (a) M. Samah, S. Merabet, M. Bouguerra, S. Ouhenia and A. Bouzaza, Kinet. Catal., 2011, 52, 34-54; (b) C.-Y. Tsay, C.-W. Wu, C.-M. Lei, F.-S. Chen and C.-K. Lin, Thin Solid Films, 2010, 519, 1516-1520.

43 F. Toney, J. Gijo, M. Siby, P. R. Rejikumar and N. V. Unnikrishnan, J. Sol-Gel Sci. Technol., 2007, 41, 163168.

44 R. K. Sahoo, A. Das, S. K. Singh and B. K. Mishra, Surf. Coat. Technol., 2016, 307, 476-483.

45 J. Lindeboom, Prog. Org. Coat., 1998, 34(1-4), 147-151.

46 E. U. Ikhuoria, F. Eireguamen, I. Aigbodion and F. A. Okieimen, Trop. J. Pharm. Res., 2004, 3, 311-317. 